\title{
Trimester-Specific Reference Ranges for Thyroid Hormones in Iranian Pregnant Women
}

\author{
Ladan Mehran, ${ }^{1}$ Atieh Amouzegar, ${ }^{1}$ Hossein Delshad, ${ }^{1}$ Sahar Askari, ${ }^{1}$ Mehdi Hedayati, \\ Golshan Amirshekari, ${ }^{1}$ and Fereidoun Azizi ${ }^{1}$ \\ ${ }^{1}$ Endocrine Research Center, Research Institute for Endocrine Sciences, Shahid Beheshti University of Medical Sciences, \\ Tehran 1985717413, Iran \\ ${ }^{2}$ Mollecular and Cellular Endocrine Research Center, Research Institute for Endocrine Sciences, \\ Shahid Beheshti University of Medical Sciences, Tehran 1985717413, Iran
}

Correspondence should be addressed to Fereidoun Azizi; azizi@endocrine.ac.ir

Received 31 October 2012; Accepted 29 April 2013

Academic Editor: John H. Lazarus

Copyright (c) 2013 Ladan Mehran et al. This is an open access article distributed under the Creative Commons Attribution License, which permits unrestricted use, distribution, and reproduction in any medium, provided the original work is properly cited.

Background. Due to many physiological changes during pregnancy, interpretation of thyroid function tests needs trimester-specific reference intervals for a specific population. There is no normative data documented for thyroid hormones on healthy pregnant women in Iran. The present survey was conducted to determine trimester-specific reference ranges for serum TSH, thyroxine (TT4), and triiodothyronine (TT3). Methods. The serum of 215 cases was analyzed for measurement of thyroid function tests by immunoassay method of which 152 iodine-sufficient pregnant women without thyroid autoantibodies and history of thyroid disorder or goiter were selected for final analysis. Reference intervals were defined as 5th and 95th percentiles. Results. Reference intervals in the first, second, and third trimesters were as follows: TSH $(0.2-3.9,0.5-4.1$, and $0.6-4.1 \mathrm{mIU} / \mathrm{l})$, TT4 (8.2-18.5, 10.120.6, and 9-19.4 $\mathrm{gg} / \mathrm{dl})$, and TT3 (137.8-278.3, 154.8-327.6, and 137-323.6 ng/dl), respectively. No correlation was found between TSH and TT4 or TT3. Significant correlation was found between TT4 and TT3 in all trimesters $(r=0.35, P<0.001)$. Conclusion. The reference intervals of thyroid function tests in pregnant women differ among trimesters. Applying trimester-specific reference ranges of thyroid hormones is warranted in order to avoid misclassification of thyroid dysfunction during pregnancy.

\section{Background}

Thyroid dysfunction, in particular hypothyroidism, can affect the health of both mother and fetus during pregnancy [1, 2]. Thyroid disorders are commonly present in pregnancy and puerperium. Hypothyroidism has a higher prevalence than hyperthyroidism (2.5 versus $0.2 \%$ ) during the gestational period [3]. Early and appropriate detection of thyroid dysfunction and timely interventions improve maternal-fetal prognosis, so application of reliable gestational specific reference values for determining thyroid disorders in pregnant women would be a necessity [4].

The vast physiological changes in maternal hormones and their binding proteins complicate the assessment of normal levels of most hormones and the interpretation of the tests' result during gestation, especially when there are no established gestation specific reference intervals, as with
Iranian population. Increase in thyroid size and production of thyroid hormones along with a 50\% increase in the daily iodine requirement may result in hypothyroidism or unveil subclinical thyroid dysfunction in the later stages of pregnancy [5].

Despite the recent development in sensitive biochemical assays and understanding gestation-dependent trends of thyroid hormones, clinically useful gestation specific reference ranges are scarce [6]. Existing results are inconsistent and should not be extrapolated due to differences in ethnicity, maternal iodine status, laboratory assay method, and rigor for selection of reference population (choice of reference population, sample size, assessment of outliers, and so forth). There is also a doubt about the validity of the results as data are mostly derived from earlier studies [7], cross-sectional studies restricted to one trimester [8-11], use of less accurate hormone assays techniques, studies on population with 
differing iodine status $[12,13]$, applying outdated statistical methods for calculating reference ranges, and cross-sectional studies on different women from different gestations instead of longitudinal self-sequential surveys [12, 14]. Estimating self-sequential reference intervals [14] has narrower variations than interindividual variations caused by sampling error in cross-sectional studies conducted on different groups and hence provides clinicians with more accurate values for proper diagnoses and management.

Considering the lack of data regarding thyroid hormones specific reference ranges in Iranian pregnant women, we carried out this longitudinal study to investigate the self-sequential longitudinal reference values for thyrotropin (TSH), total thyroxine (TT4), and total triiodothyronine (TT3), in normal Tehranian pregnant women.

\section{Methods}

2.1. Study Population. A total of 466 Iranian pregnant women, who had the same ethnicity of Persians, in the first trimester of pregnancy attending antenatal care clinics in the mother and child health care centers of two general hospitals of Tehran were consecutively recruited from November 2004 to November 2006. Only women with singleton pregnancies were enrolled. Inclusion criteria required documentation that thyroid-related measurements were available in all of the three trimesters. Of 466 women who were referred in the first trimester, 147 subjects were excluded because of preexisting thyroid disorders or nodules; those taking medications affecting thyroid function and those not available in all trimesters or lost to follow-up (referring elsewhere for delivery, nonviable pregnancy) were excluded, and 219 healthy pregnant women were selected. A further 67 subjects were excluded due to laboratory results of positive serum thyroid peroxidase and thyroglobulin antibodies (TPOAb > $40 \mathrm{IU} / \mathrm{mL}$ or $\mathrm{Tg} \mathrm{Ab}>100 \mathrm{IU} / \mathrm{mL}$ ) (47 subjects), low urinary iodine level $(<150 \mu \mathrm{g} / \mathrm{dL}$ in two out of 3 sample measurements in the first trimester) (34 subjects), and enlarged thyroid gland (thyroid volume greater than $30 \mathrm{~mL}$ ) by ultrasonography (9 subjects). None had overt hypo- (TSH $>4.5 \mathrm{mIU} / \mathrm{L}$ and $\mathrm{T} 4<5.5)$ or hyperthyroidism $(\mathrm{TSH}<0.1 \mathrm{mIU} / \mathrm{L} \& \mathrm{~T} 4$ $>14.5$ ) or subclinical hypothyroidism (TSH $>10 \mathrm{mIU} / \mathrm{L}$ ). Those with subclinical hyperthyroidism (serum TSH levels under $0.1 \mathrm{mIU} / \mathrm{L}$ ) were not excluded due to normal TSH suppression at pregnancy. Finally 152 healthy iodinesufficient women with viable, singleton pregnancies comprised the cohort study (Figure 1).

2.2. Methods. Trained midwives informed participants about the rationale of the study to obtain written consent to allow for laboratory measurements and thyroid ultrasonography. Obstetric history was taken using a standard questionnaire, and physical examination was performed. Gestational age was calculated from the first day of the last normal menstrual period, and gestational age $<14,14-27$, and $>28$ weeks comprised the first, second, and third trimesters of pregnancy. Serum samples were taken in all three trimesters for assessment of TSH, TT4, and TT3, thyroperoxidase antibody (TPOAb), and thyroglobulin antibody (Tg $\mathrm{Ab}$ ).

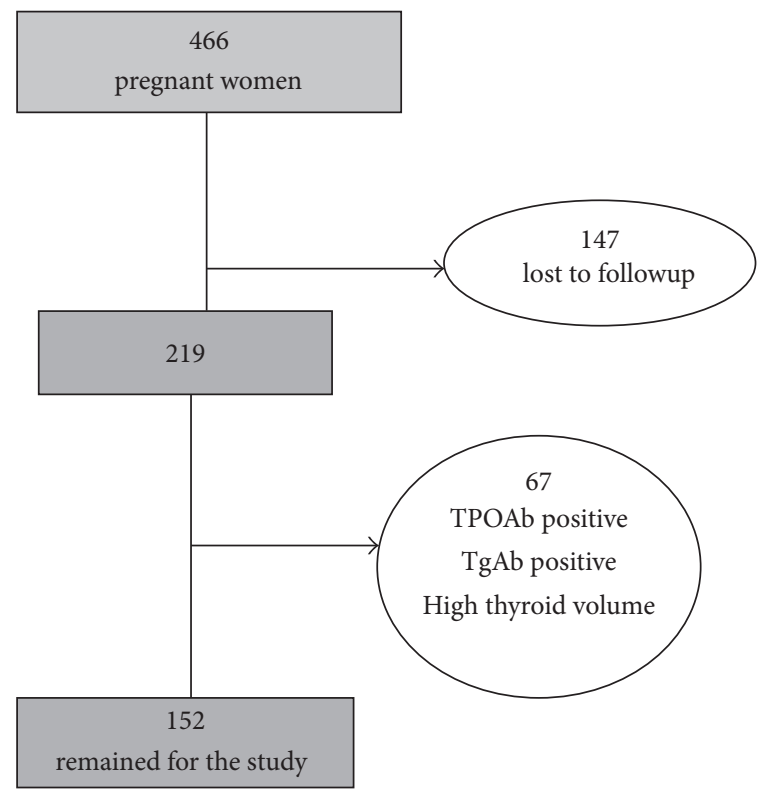

FIGURE 1

At initial presentation, before the end of the first trimester, three urine samples and in each of the second and third trimesters one urine sample were obtained for measurement of urinary iodine concentration (UIC). In all of the trimesters thyroid volume of pregnant women was also measured using ultrasound (Japan, Aloka, Portable 7.5 MHZ, SSD 2100 DX). The volume of each lobe was calculated by the formula $V(\mathrm{~mL})=0.000479 \times$ length $\times$ width $\times$ thickness $(\mathrm{mm})$.

2.3. Laboratory Measurements. Urinary iodine concentration was measured in random urine samples using a manual method, based on the Sandell-kolthoff technique [25]. Measurement of TT4 and TT3 were done using the radioimmunoassay (RIA) method, and TSH was measured by immunoenzymometric assay (IRMA) using commercial kits (Izotop, Budapest, Hungray) and gamma counters (Wallac Wizard, Wallac Oy, Turku, Finland). Intra- and interassay coefficients of variations (CV) were 3.3 and $6.2 \%$ for TT4, 6.7 and $7.8 \%$ for TT3, and 3.9 and $7.1 \%$ for TSH, respectively.

2.4. Statistical Analysis. Since serum TSH had a nonGaussian distribution, log-transformed values were used for TSH. The reference interval of each hormone in each trimester was determined by calculating the 5th and 95th percentiles (i.e., a central $90 \%$ interval) using the bootstrap technique. Repeated measures were employed to compare differences in thyroid hormones among groups with different gestational ages. Pearson's correlation was applied to evaluate the correlation of log-transformed TSH values with TT4 and TT3. All $P$ values below 0.05 were considered statistically significant.

\section{Results}

Mean age of the whole study population (216 pregnant women) was $25.3 \pm 5$ years (range of 18-45). Thirty subjects 
TABLE 1: Average trimester specific values of gestational age, urinary iodine concentration and thyroid volumes in 152 healthy pregnant women.

\begin{tabular}{lccc}
\hline Variable & 1st trimester & 2nd trimester & 3rd trimester \\
\hline Gestational time (week) & $12.2 \pm 3.7^{*}$ & $23.8 \pm 1.8$ & $35.7 \pm 1.5$ \\
Urinary iodine $(\mu \mathrm{g} / \mathrm{dL})$ & $228(169,285)^{\dagger}$ & $166(108,267)$ & $143(85,232)$ \\
Thyroid volume $(\mathrm{mL})$ & $9.05 \pm 4.1^{*}$ & $10.15 \pm 4.3$ & $10.9 \pm 5.1$ \\
\hline${ }^{*}$ Mean $+\mathrm{SD}^{\dagger}$ medin values (inter quartile range)
\end{tabular}

TABLE 2: Gestation specific percentile values for TSH, TT4, and TT3 in a self sequential cohort of 152 pregnant women with normal singleton pregnancies.

\begin{tabular}{lccc}
\hline & \multicolumn{3}{c}{ Observed centiles } \\
& 5th & 50th & 95th \\
\hline TSH (mU/L) & & & \\
$\quad$ First trimester & 0.2 & 1.5 & 3.9 \\
$\quad$ Second trimester & 0.5 & 1.8 & 4.1 \\
$\quad$ Third trimester & 0.6 & 1.8 & 4.1 \\
TT4 ( $\mu$ g/dL) & & & \\
$\quad$ First trimester & 8.2 & 12.9 & 18.5 \\
Second trimester & 10.1 & 14 & 20.6 \\
$\quad$ Third trimester & 9.0 & 13.4 & 19.4 \\
TT3 (ng/dL) & & & \\
$\quad$ First trimester & 138 & 190 & 278 \\
$\quad$ Second trimester & 155 & 221 & 328 \\
$\quad$ Third trimester & 137 & 228 & 324 \\
\hline
\end{tabular}

(13.9\%) were TPO Ab positive, 34 (15.4\%) were $\mathrm{Tg} \mathrm{Ab}$ positive, and 17 (7.9\%) were positive for both TPO Ab and $\mathrm{Tg} \mathrm{Ab}$. After applying exclusion criteria, 152 pregnant women remained and entered the study cohort. Mean age of the cohort was $24.8 \pm 4.9$ years, of which 22 subjects $(14.6 \%)$ were aged under 20 years, 106 (69.5\%) between 20 and 30 years, and $24(15.9 \%)$ over 30 years. The trimester average values of gestational age, urinary iodine, and thyroid volume of the study cohort are given in Table 1 . Mean \pm SD (range) gestational age at the study visits during the first, second, and third trimesters were $12.2 \pm 3.7,23.8 \pm 1.8$, and $35.7 \pm 1.5$ weeks, respectively.

Table 2 shows trimester specific percentiles (5th, 50th, and 95th) for TSH, TT4, and TT3 based on the data of this study. The limits of the reference intervals were calculated as $p^{5}-p^{95}$. Significant difference was observed in average values of TSH among trimesters $(P=0.008)$. TSH mean values rose significantly in the second trimester $(P=0.007)$ followed by a nonsignificant decrease in the third trimester $(P=0.8)$. The TSH reference intervals showed that lower TSH reference limit of 0.2 occurred in the first trimester in comparison with the 2nd and 3rd trimesters of 0.5 and 0.6 , respectively. The upper reference range of TSH of 3.9 in the first trimester increased to 4.1 in the second trimester and remained unchanged in the last trimester.

The percentiles and average values of both TT4 and TT3 increased markedly after the first trimester reached a peak in the second trimester $(P<0.001)$ and declined in the third

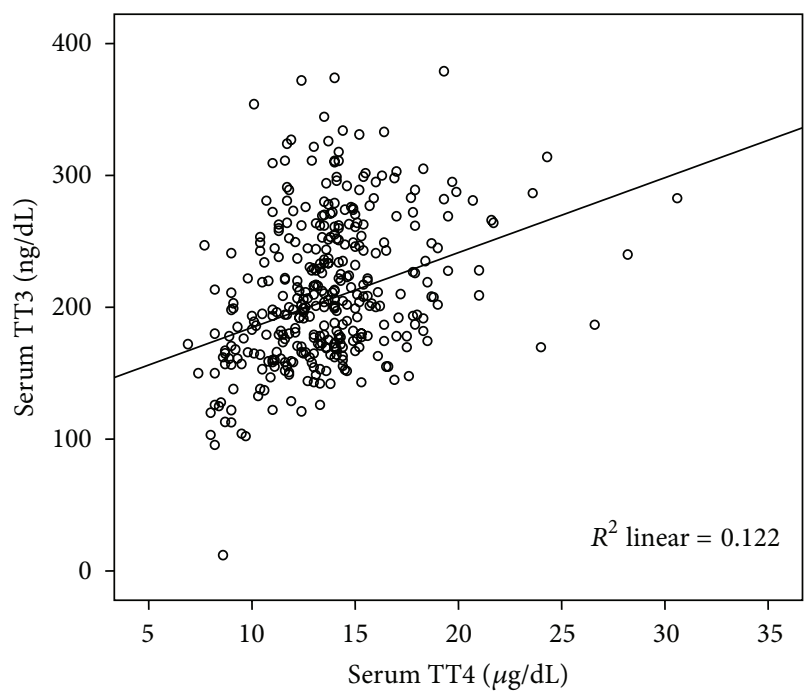

FIGURE 2: Scatter plot of correlation between TT4 and TT3 $(r=0.35$, $P<0.001)$.

( $P=0.01$ for TT4 and $P=0.5$ for TT3) (Table 2$)$. Significant difference was found in values of TT4 $(P=0.05)$ and TT3 $(P<0.001)$ between the first and the third trimesters.

Serum TSH had no significant correlation with TT4 and TT3. Significant correlations were found between TT4 and TT3 in all trimesters $(r=0.35, P<0.001)$ (Figure 2). Considering each trimester separately, the correlation was stronger in the first trimester $(r=0.5, P<0.001)$ compared with second and third trimesters (both, $r=0.26, P=0.004$ ).

\section{Discussion}

The present survey provides trimester-specific reference ranges for serum TSH and thyroid hormones during pregnancy in Tehran, I.R. Iran. Differences observed in the derived reference intervals between different gestations and in comparison with those provided by manufacturers in nonpregnant adults, and reports from the other countries provide further evidence of the importance of applying gestational age-specific reference value for a specific population in order to avoid misclassification of patients with thyroid dysfunction during pregnancy.

The major discrepancy in TSH reference values in our data compared with other reports mainly exists in the TSH upper reference limit, which is relatively higher than most of the other reports. However studies by Marwaha et al. in India [16] and Dhatt et al. in the United Arab Emirates [21] reported much higher TSH upper reference values than the present survey. Our TSH reference limits approximate those of Yu et al. from China [14], who used the same self-sequential design; we, however, used the 5th and 95th percentiles as the reference limits instead of the 2.5 th and 97.5 th used in their study. In agreement with previous studies our results indicate that the derived reference intervals of TSH for pregnant women were different (narrower and lower) from those proposed by kit manufacturers (0.2-4.5 mIU/L). Had we considered reference range of nonpregnant adults for a pregnant population, 
TABLE 3: Summary of worldwide studies reporting trimester-specific reference intervals for TSH during pregnancy.

\begin{tabular}{|c|c|c|c|c|c|c|}
\hline \multirow{2}{*}{ Study } & \multirow{2}{*}{ Country } & \multirow{2}{*}{$\begin{array}{c}\text { Sample size and } \\
\text { Design }\end{array}$} & \multirow{2}{*}{ Centiles' used } & \multicolumn{3}{|c|}{ TSH reference intervals } \\
\hline & & & & 1st trimester & 2nd trimester & 3rd trimester \\
\hline Panesar et al. [12], 2001 & China & $\begin{array}{c}343 \\
\text { cohort }\end{array}$ & 2.5th, 97.5th & $\begin{array}{l}n=158 \\
0.03-2.3\end{array}$ & $\begin{array}{l}n=117 \\
0.03-3.1\end{array}$ & $\begin{array}{c}n=76 \\
0.13-3.5\end{array}$ \\
\hline Soldin et al. [6], 2007 & USA & $\begin{array}{c}261 \\
\text { cross-sectional }\end{array}$ & 2.5th, 97.5th & $\begin{array}{c}n=71 \\
0.24-2.99\end{array}$ & $\begin{array}{c}n=83 \\
0.46-2.95\end{array}$ & $\begin{array}{c}n=62 \\
0.43-2.78\end{array}$ \\
\hline Stricker et al. [15], 2007 & Switzerland & $\begin{array}{c}2272 \\
\text { cross-sectional }\end{array}$ & 2.5th, 97.5th & $\begin{array}{c}n=783 \\
0.09-2.82\end{array}$ & $\begin{array}{l}n=528 \\
0.2-2.79\end{array}$ & $\begin{array}{l}n=501 \\
0.31-2.9\end{array}$ \\
\hline Marwaha et al. [16], 2008 & India & $\begin{array}{c}541 \\
\text { cross-sectional }\end{array}$ & 5th, 95th & $\begin{array}{c}n=107 \\
0.6-5\end{array}$ & $\begin{array}{c}n=137 \\
0.43-5.78\end{array}$ & $\begin{array}{c}n=87 \\
0.74-5.7\end{array}$ \\
\hline $\begin{array}{l}\text { Bocos-Terraz et al. [17], } \\
2009\end{array}$ & Spain & $\begin{array}{c}1198 \\
\text { cross-sectional }\end{array}$ & 2.5th, 97.5th & $\begin{array}{c}n=481 \\
0.03-2.65\end{array}$ & $\begin{array}{c}n=243 \\
0.12-2.64\end{array}$ & $\begin{array}{c}n=297 \\
0.23-3.56\end{array}$ \\
\hline Yu et al. [14], 2010 & China & $\begin{array}{l}538 \\
\text { cohort }\end{array}$ & 2.5th, 97.5th & $\begin{array}{c}n=301 \\
0.02-3.65\end{array}$ & $\begin{array}{c}n=301 \\
0.36-3.46\end{array}$ & $\begin{array}{c}n=301 \\
0.44-5.04\end{array}$ \\
\hline Yan et al. [18], 2011 & China & $\begin{array}{c}505 \\
\text { cross-sectional }\end{array}$ & 2.5th, 97.5th & $\begin{array}{l}n=168 \\
0.03-4.51\end{array}$ & $\begin{array}{l}n=168 \\
0.05-4.5\end{array}$ & $\begin{array}{c}n=169 \\
0.47-4.54\end{array}$ \\
\hline Azizi et. al, 2012 [19] & Iran & $\begin{array}{c}261 \\
\text { cohort }\end{array}$ & 5th, 95th & $\begin{array}{r}n=216 \\
0.2-3.9\end{array}$ & $\begin{array}{r}n=216 \\
0.5-4.1\end{array}$ & $\begin{array}{r}n=216 \\
0.6-4.1\end{array}$ \\
\hline Haddow et al. [20], 2004 & USA & $\begin{array}{l}1126 \\
\text { cohort }\end{array}$ & 5th, 95th & $\begin{array}{l}n=1005 \\
0.08-2.73\end{array}$ & $\begin{array}{l}n=1005 \\
0.39-2.70\end{array}$ & - \\
\hline Dhatt et al. [21], 2006 & United Arab Emirates & $\begin{array}{c}1140 \\
\text { cross-sectional }\end{array}$ & - & $\begin{array}{c}\text { United Arabs } \\
0.06-8.3, n=97 \\
\text { other Arabs } \\
0.04-9.3 \\
n=122 \\
\text { Asians } \\
0.12-7.4, n=79\end{array}$ & $\begin{array}{c}\text { United Arabs } \\
0.17-5.9 \\
\text { other Arabs } \\
0.23-5.7 \\
\text { Asians } \\
0.3-5.5\end{array}$ & - \\
\hline $\begin{array}{l}\text { Lambert-Messerlian et al. } \\
{[22], 2008}\end{array}$ & USA & $\begin{array}{l}9562 \\
\text { cohort }\end{array}$ & 98th, 2th & $\begin{array}{r}n=9562 \\
0.13-4.15\end{array}$ & $\begin{array}{l}n=9562 \\
0.36-3.77\end{array}$ & - \\
\hline Santiago et al. [23], 2011 & Spain & $\begin{array}{c}429 \\
\text { cross-sectional }\end{array}$ & 97th, 3th & $\begin{array}{c}n=279 \\
0.23-4.18\end{array}$ & $\begin{array}{c}n=210 \\
0.36-3.89\end{array}$ & - \\
\hline Karakosta et al. [24], 2011 & Greece & $\begin{array}{c}425 \\
\text { cohort }\end{array}$ & 2.5th, 97.5th & $\begin{array}{c}n=143 \\
0.05-2.53\end{array}$ & $\begin{array}{c}n=260 \\
0.18-2.73\end{array}$ & - \\
\hline
\end{tabular}

women with subclinical hypothyroidism would have been missed and classified in the normal group. For establishment of thyroid hormone reference intervals, many factors such as ethnic background, maternal iodine status, laboratory measurement techniques, definition of reference population, exclusion criteria, and method of statistical analysis need to be considered, which may justify the inconsistency in the results of different surveys. Table 3 summarizes and compares (Figure 3) the reports of worldwide studies performed to date regarding trimester-specific reference intervals of TSH in pregnant women $[15,17,18,20,22-24]$. The studies were compared considering nationality, sample size and study design and method, although it would be more useful to make comparisons with specific factors in mind: for example, comparisons with other studies of women of similar ethnic origin which is more useful than country of origin or studies using the same assay platform, and so forth.

Trimester-wise reference intervals for TT3 and TT4 were determined only in two studies by Yan et al. from China [18] and Soldin et al. [26]; both reported lower values for these hormones compared with our results. Trimester specific ranges in the first, second, and third trimesters in the study by Soldin et al. were $6.3-14.6,6.4-14.8$, and $6.3-16.7 \mu \mathrm{g} / \mathrm{dL}$ for TT4 and 92-218, 112-278, and 111-265 ng/dL for TT3, respectively, using immunoassay method. In this study higher levels for TT4 and lower levels for TT3 in each case were reported using isotope dilution tandem mass spectrometry (LC/MS/MS). There was a significant correlation in TT4 measurements between IA and LC methods in all trimesters; in contrast to $\mathrm{T} 3$, the measurements of which were weakly correlated between the two methods. While TT4 was not significantly different during any trimester, TT3 increased significantly with the progression of pregnancy. T3 and T4 tended to be associated in all trimesters except for the third trimester. In the Chinese study by Yan et al. TT4 and TT3 were markedly increased at the first trimester, peaked in the second trimester, and declined slightly in the third trimester [18].

The strengths of our study include the strict inclusion criteria used as we considered maternal iodine status by measurement of urinary iodine level, thyroid size by ultrasonography and positivity for both TPO Ab and Tgb A, 


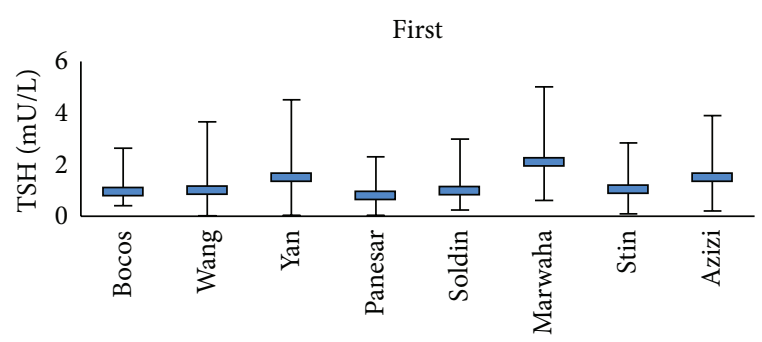

(a)

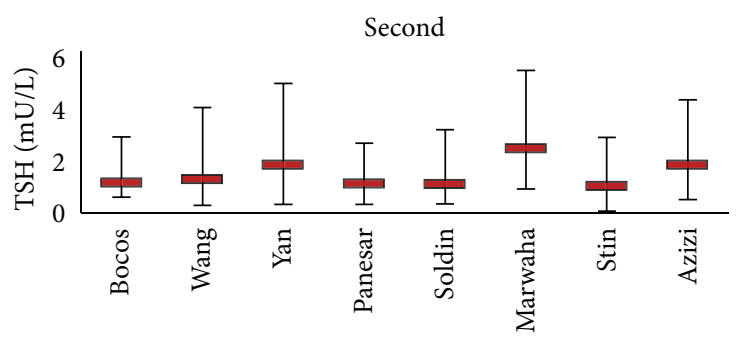

(b)

Third

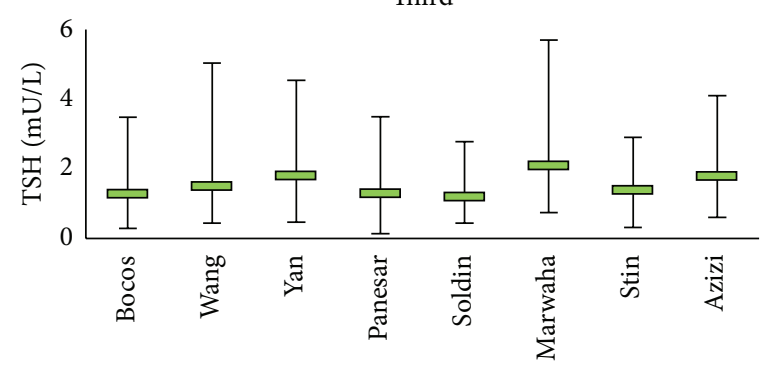

(c)

FIgURE 3: Comparison of trimester specific TSH reference ranges reported worldwide.

factors which have not been considered together in most studies. The exclusion criteria in the present study is specific and derived from the combination of recommendations by National Academy of Clinical Biochemistry (NACB) [27] and the National Health and National Examination Survey (NHANES) [28] to provide a well-defined healthy population. In addition, maternal iodine sufficiency in our survey is verified by urinary iodine measurement and not by just the assumption of iodine sufficiency in a specific area as done in most studies. Another strength of much importance is the self-sequential longitudinal design of our study which reduces the variation in reference intervals by omitting interindividual variations and reflects the changes of thyroid hormones during pregnancy more realistically than cross-sectional studies from different women in different stages. Additional strengths of our study are the adequacy of the sample size required for estimating reference values based on clinical laboratory standards (NCCLS) [29] and relevant application of nonparametric or parametric analyses based on the distribution of variables in our data, an important issue which has been ignored in some studies.

Our study does have some weaknesses. We did not have access to information on gestational and prenatal complications like hyperemesis, preeclampsia, gestational diabetes, premature delivery and fetal death, or anomalies and therefore did not consider them in the exclusion criteria. Gestational ages were based on the last menstrual period and not confirmed by ultrasonography. The current survey is limited by lack of data regarding the pre- and postpregnancy period although it does not interfere with the main goal of estimating trimester-wise reference value in our survey. It would have been better to have a sample of nonpregnant women simultaneously which would enable us to compare the changes occurring in these hormones more accurately.

\section{Conclusion}

The reference intervals of thyrotropin and thyroid hormones found in the current study differ from those reported by other countries and necessitate the importance of applying trimester-specific reference ranges specific to each population. Considering that Tehran is an area of iodine sufficiency and that women with urinary iodine excretion below $150 \mu \mathrm{g} / \mathrm{dL}$ were excluded from the study, our results can be generalized to more than one million Iranian pregnant women each year in order to accurately detect thyroid dysfunction during pregnancy.

\section{Conflict of Interests}

The authors declare that they have no competing interests.

\section{Acknowledgments}

This study was supported by financial grants from the Research Institute for Endocrine Sciences (RIES), Shahid Beheshti University of Medical Sciences, Tehran, Iran. The authors would like to acknowledge laboratory personnel of the RIES for their assistance. The authors also thank Ms. Niloofar Shiva for language editing of the paper.

\section{References}

[1] J. E. Haddow, G. E. Palomaki, W. C. Allan et al., "Maternal thyroid deficiency during pregnancy and subsequent neuropsychological development of the child," The New England Journal of Medicine, vol. 341, no. 8, pp. 549-555, 1999.

[2] I. Idris, R. Srinivasan, A. Simm, and R. C. Page, "Maternal hypothyroidism in early and late gestation: effects on neonatal 
and obstetric outcome," Clinical Endocrinology, vol. 63, no. 5, pp. 560-565, 2005.

[3] R. Z. Klein, J. E. Haddow, J. D. Faix et al., "Prevalence of thyroid deficiency in pregnant women," Clinical Endocrinology, vol. 35, no. 1, pp. 41-46, 1991.

[4] J. H. Lazarus, "Screening for thyroid dysfunction in pregnancy: is it worthwhile?" Journal of Thyroid Research, vol. 2011, Article ID 397012, 4 pages, 2011.

[5] D. Glinoer, "What happens to the normal thyroid during pregnancy?" Thyroid, vol. 9, no. 7, pp. 631-635, 1999.

[6] O. P. Soldin, D. Soldin, and M. Sastoque, "Gestation-specific thyroxine and thyroid stimulating hormone levels in the United States and worldwide," Therapeutic Drug Monitoring, vol. 29, no. 5, pp. 553-559, 2007.

[7] M. de Swiet, Ed., Thyroid Disease and Pregnancy by Joanna Girling: Medical Disorders in Obstetric Practice, Blackwell, 4th edition, 2002.

[8] D. Springer, T. Zima, and Z. Limanova, "Reference intervals in evaluation of maternal thyroid function during the first trimester of pregnancy," European Journal of Endocrinology, vol. 160, no. 5, pp. 791-797, 2009.

[9] S. L. La'ulu and W. L. Roberts, "Second-trimester reference intervals for thyroid tests: the role of ethnicity," Clinical Chemistry, vol. 53, no. 9, pp. 1658-1664, 2007.

[10] R. M. Gilbert, N. C. Hadlow, J. P. Walsh et al., "Assessment of thyroid function during pregnancy: first-trimester (weeks 9-13) reference intervals derived from Western Australian women," Medical Journal of Australia, vol. 189, no. 5, pp. 250-253, 2008.

[11] L. García de Guadiana Romualdo, M. González Morales, C. Martín-Ondarza González Mdel et al., "Evaluation of thyroid function during pregnancy: first-trimester reference intervals for thyroid-stimulating hormone and free thyroxine," Endocrinología y Nutrición, vol. 57, pp. 290-295, 2010.

[12] N. S. Panesar, C. Y. Li, and M. S. Rogers, "Reference intervals for thyroid hormones in pregnant Chinese women," Annals of Clinical Biochemistry, vol. 38, no. 4, pp. 329-332, 2001.

[13] A. Price, O. Obel, J. Cresswell et al., "Comparison of thyroid function in pregnant and non-pregnant Asian and western Caucasian women," Clinica Chimica Acta, vol. 308, no. 1-2, pp. 91-98, 2001.

[14] B. Yu, Q. W. Wang, R. P. Huang et al., "Establishment of self-sequential longitudinal reference intervals of maternal thyroid function during pregnancy," Experimental Biology and Medicine, vol. 235, no. 10, pp. 1212-1215, 2010.

[15] R. Stricker, M. Echenard, R. Eberhart et al., "Evaluation of maternal thyroid function during pregnancy: the importance of using gestational age-specific reference intervals," European Journal of Endocrinology, vol. 157, no. 4, pp. 509-514, 2007.

[16] R. K. Marwaha, S. Chopra, S. Gopalakrishnan et al., "Establishment of reference range for thyroid hormones in normal pregnant Indian women," British Journal of Obstetrics and Gynaecology, vol. 115, no. 5, pp. 602-606, 2008.

[17] J. Bocos-Terraz, S. Izquierdo-Álvarez, J. Bancalero-Flores et al., "Thyroid hormones according to gestational age in pregnant Spanish women," BMC Research Notes, vol. 2, article 237, 2009.

[18] Y. Q. Yan, Z. L. Dong, L. Dong et al., “Trimester-and methodspecific reference intervals for thyroid tests in pregnant Chinese women: methodology, euthyroid definition and iodine status can influence the setting of reference intervals," Clinical Endocrinology, vol. 74, no. 2, pp. 262-269, 2011.
[19] F. Azizi, L. Mehran, A. Amouzegar et al., "Establishment of the trimester-specific reference range for free thyroxine index," Thyroid, vol. 23, no. 3, pp. 354-359, 2013.

[20] J. E. Haddow, G. J. Knight, G. E. Palomaki, M. R. McClain, and A. J. Pulkkinen, "The reference range and within-person variability of thyroid stimulating hormone during the first and second trimesters of pregnancy," Journal of Medical Screening, vol. 11, no. 4, pp. 170-174, 2004.

[21] G. S. Dhatt, G. Griffin, and M. M. Agarwal, “Thyroid hormone reference intervals in an ambulatory Arab population on the Abbott Architect i2000 immunoassay analyzer," Clinica Chimica Acta, vol. 364, no. 1-2, pp. 226-229, 2006.

[22] G. Lambert-Messerlian, M. McClain, J. E. Haddow et al., "First- and second-trimester thyroid hormone reference data in pregnant women: a FaSTER (First- and Second-Trimester Evaluation of Risk for aneuploidy) Research Consortium study," American Journal of Obstetrics and Gynecology, vol. 199, no. 1, pp. 62-66, 2008, Erratum in: American Journal of Obstetrics \& Gynecology, Vol.199, article 326, 2008.

[23] P. Santiago, M. Berrio, P. Olmedo et al., "Reference values for thyroid hormones in the population of pregnant women in jaen (Spain)," Endocrinologia y Nutricion, vol. 58, no. 2, pp. 62-67, 2011.

[24] P. Karakosta, L. Chatzi, E. Bagkeris et al., "First- and secondtrimester reference intervals for thyroid hormones during pregnancy in, "Rhea" Mother-Child Cohort, Crete, Greece," Journal of Thyroid Research, vol. 2011, Article ID 490783, 12 pages, 2011.

[25] ICCIDD, WHO, and UNICEF, Assessment of Iodine Deficiency Disorders and Monitoring Their Elimination, A Guide for Programme Managers, World Health Organization, 3rd edition, 2007.

[26] O. P. Soldin, L. Hilakivi-Clarke, E. Weiderpass, and S. J. Soldin, "Trimester-specific reference intervals for thyroxine and triiodothyronine in pregnancy in iodine-sufficient women using isotope dilution tandem mass spectrometry and immunoassays," Clinica Chimica Acta, vol. 349, no. 1-2, pp. 181-189, 2004.

[27] Z. Baloch, P. Carayon, B. Conte-Devolx et al., "Laboratory medicine practice guidelines. Laboratory support for the diagnosis and monitoring of thyroid disease," Thyroid, vol. 13, no. 1, pp. 3-126, 2003.

[28] J. G. Hollowell, N. W. Staehling, W. Dana Flanders et al., "Serum TSH, T4, and thyroid antibodies in the United States population (1988 to 1994): National Health and Nutrition Examination Survey (NHANES III)," Journal of Clinical Endocrinology and Metabolism, vol. 87, no. 2, pp. 489-499, 2002.

[29] National Committee for Clinical Laboratory, How to Define and Determine Reference Intervals in the Clinical Laboratory, Approved Guideline (NCCLS Document C28-A2), National Committee for Clinical Laboratory, Wayne, Mich, USA, 2th edition, 1995. 


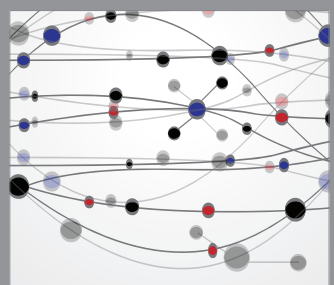

The Scientific World Journal
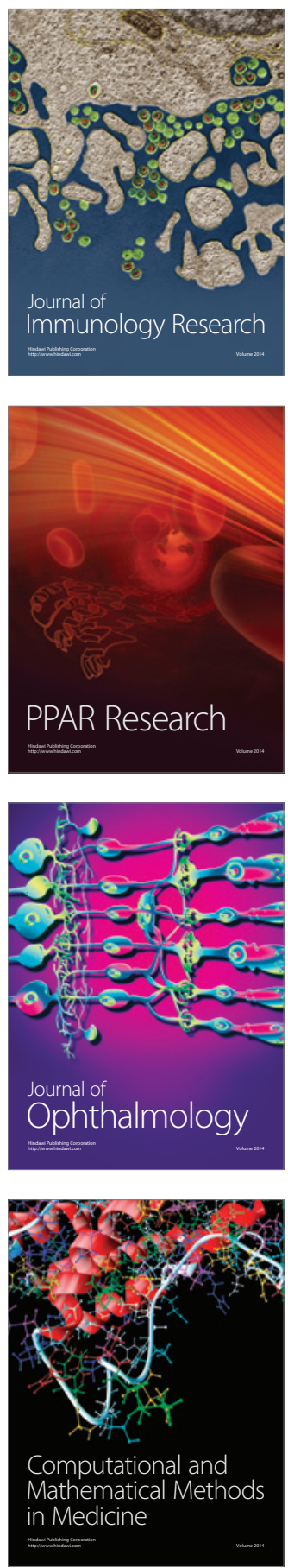

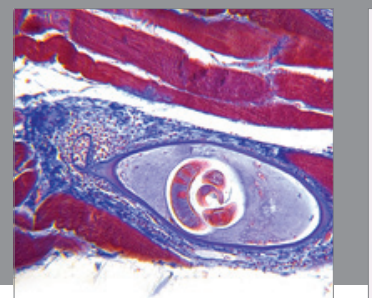

Gastroenterology

Research and Practice
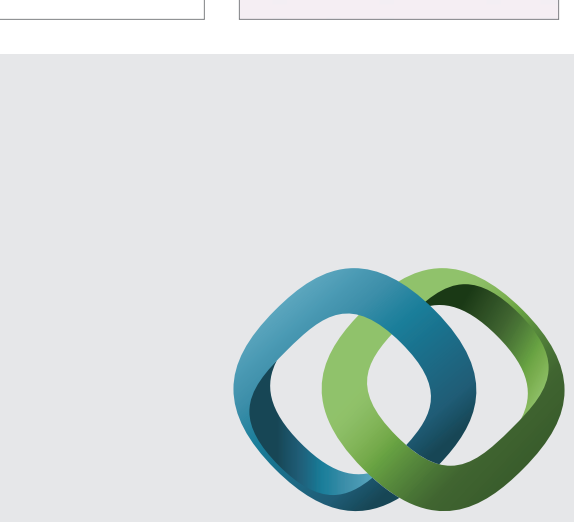

\section{Hindawi}

Submit your manuscripts at

http://www.hindawi.com
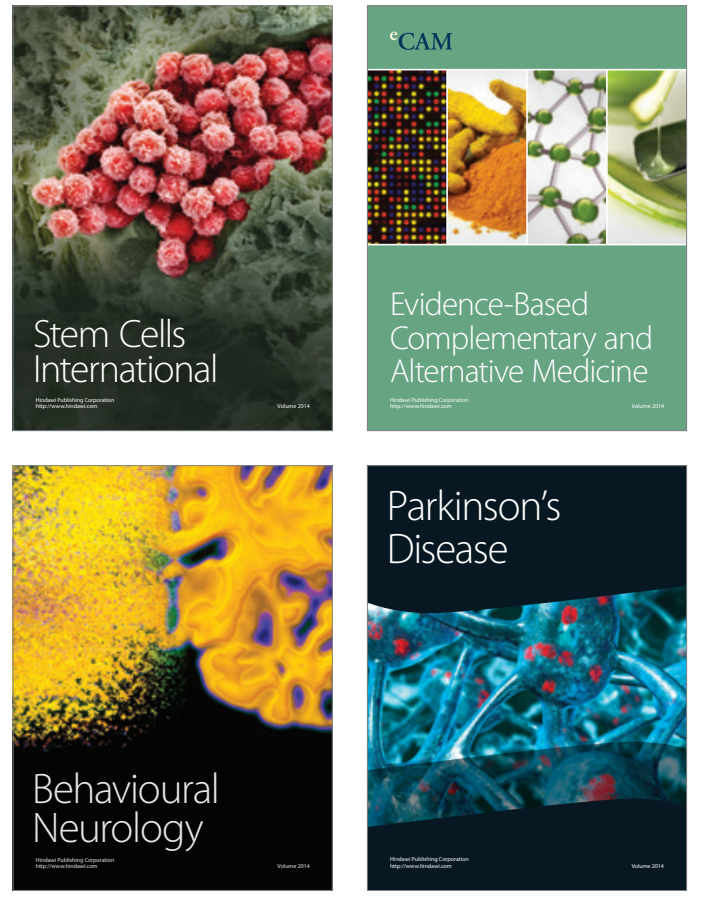
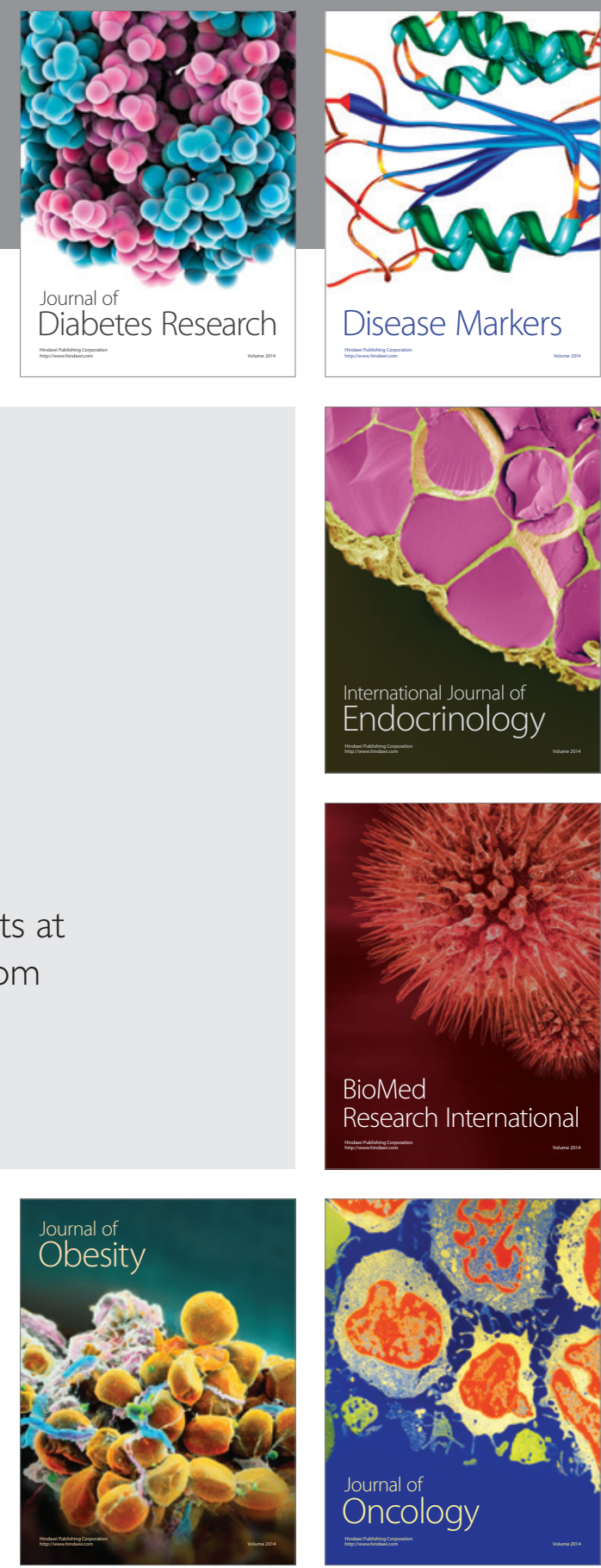

Disease Markers
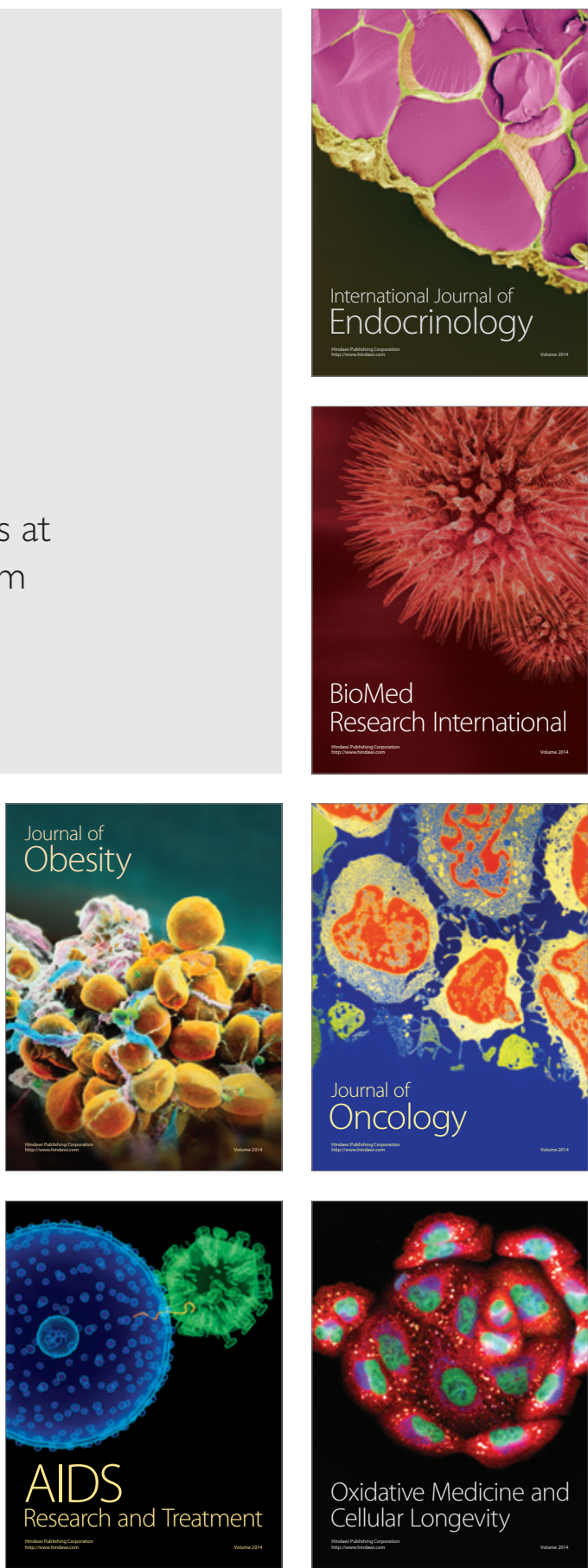